\title{
A CORRELATIONAL STUDY OF ELECTROCARDIOGRAM FINDINGS WITH SEVERITY OF COPD IN A TERTIARY CARE CENTRE
}

\author{
Saurabh Singhal1, Gagandeep Kaur², Varun Sisodia ${ }^{3}$
}

${ }_{1}^{1}$ Assistant Professor, Department of General Medicine, KDMCHRC, Mathura, Uttar Pradesh, India.

${ }^{2}$ Assistant Professor, Department of Community Medicine, KDMCHRC, Mathura, Uttar Pradesh, India.

${ }^{3}$ Assistant Professor, Department of General Surgery, KDMCHRC, Mathura, Uttar Pradesh, India.

\begin{abstract}
BACKGROUND

Chronic obstructive pulmonary disease is a common and preventable disease, which has great implications on health. It is a major cause of morbidity and mortality worldwide, especially in rural areas.

Aim- To study correlation between ECG changes and spirometric parameters in patients with COPD.

MATERIALS AND METHODS

A prospective observational study was conducted in our tertiary care centre. We have studied $50(\mathrm{~N}=50)$ patients diagnosed as COPD admitted in medical ward. Diagnosis of COPD was made on the basis of history, chest x-ray findings and GOLD criteria based on spirometry. We categorised them into Mild (FEV1/FVC $<0.7$ and FEV1 is $>80 \%$ predicted), Moderate (FEV1/FVC $<0.7$ and FEV1 is between $50-80 \%$ predicted), Severe (FEV1/FVC $<0.7$ and FEV1 between $30-50 \%$ of predicted) and Very Severe (FEV1/FVC $<0.7$ and FEV1 is $<30 \%$ predicted). Mild group included 2 patients, moderate group 14 patients, severe group consisted of 23 patients and very severe group consisted of 11 patients. We studied the electrocardiographic profile of the moderate, severe and very severe group patients, which includes 48 patients.
\end{abstract}

\section{RESULTS}

The study includes $50(\mathrm{~N}=50)$ patients diagnosed as COPD in our tertiary care centre. Out of 50 patients, 43 were male and 7 were female patients. The most frequent ECG changes were P-pulmonale and Right Axis Deviation of QRS complex seen in grade II and III severity, which is statistically significant. However, Right Ventricular Hypertrophy (RVH) pattern, RBBB and low voltage complexes were seen less commonly and thus were statistically not significant. More ECG changes were seen in COPD patients with low FEV1/FVC \% values (probably due to increase in residual volume with reduction in FEV1/FVC ratio).

\section{CONCLUSION}

Diagnosis of COPD is established on the basis of history and spirometric examination. Electrocardiographic changes are commonly seen as the severity of the COPD increases. The most frequent ECG change observed is P-pulmonale and Right Axis Deviation of QRS complex seen in grade II and III severity. So, ECG can be considered as an alternative parameter when spirometry is not available.

\section{KEY WORDS}

COPD, Electrocardiography, Cor Pulmonale, P-Pulmonale, Right Axis Deviation, RV Hypertrophy.

HOW TO CITE THIS ARTICLE: Singhal S, Kaur G, Sisodia V. A correlational study of electrocardiogram findings with severity of COPD in a tertiary care centre. J. Evolution Med. Dent. Sci. 2018;7(26):3000-3003, DOI: 10.14260/jemds/2018/675

\section{BACKGROUND}

Chronic Obstructive Pulmonary Disease (COPD) is a major cause of chronic morbidity and mortality throughout the world. It accounts for a substantial number of visits to general physician, emergency department, hospital admissions and also a cause for frequent absence from work.(1)

Across the world, tobacco smoking is the leading risk factor for COPD.(4) Both active and passive smoking account for respiratory symptoms. Occupational exposure to organic and inorganic dusts, chemical agents and fumes are other risk factors for COPD. $(5,6)$ There is growing evidence that indoor

'Financial or Other Competing Interest': None.

Submission 15-05-2018, Peer Review 07-06-2018,

Acceptance 14-06-2018, Published 25-06-2018.

Corresponding Author:

Saurabh Singhal,

D/B/301, Radha Valley,

Mathura, Uttar Pradesh, India.

E-mail: singhalsaurabh83@gmail.com

DOI: $10.14260 /$ jemds $/ 2018 / 675$ air pollution from biomass cooking and heating in poorly ventilated dwellings is an important risk factor for COPD.(2)

Cough is often the first and most common symptom of COPD. Cough may be productive or unproductive.(3) Cough with sputum production is present in about $30 \%$ of patients. These symptoms may vary from day to day. Breathlessness, wheezing and chest tightness are other accompanying symptoms. Fatigue, weight loss and anorexia are other problems seen in patients with severe and very severe COPD. Spirometry gives an objective measurement of airflow limitation.(2) On the basis of GOLD criteria, COPD is graded into 4 grades (Mild, Moderate, Severe and Very Severe disease) according to spirometric parameters. (4)

The major morbidity of COPD is due to its effect on cardiovascular system, which is mainly due to pulmonary arterial hypertension ultimately leading to cor pulmonale. Cor pulmonale is an important cause of mortality in patients with COPD.(5) Since the electrocardiogram is a very simple and convenient bedside investigation, it would be of great importance if a high degree of correlation is established between ECG and spirometric studies (which indicate the severity of COPD). 


\section{Aim and Objective of the study}

To study correlation between ECG changes and spirometric parameters in patients with COPD.

\section{MATERIALS AND METHODS}

\section{Type of Study}

A prospective observational study from 2016 August to 2017 August.

\section{Place of Study}

Department of Medicine, K. D. Medical College, Mathura.

\section{Inclusion Criteria}

Adult males and females aged more than 35 years with a history suggestive of chronic obstructive pulmonary airway disease were selected at random from the Outpatient Department of KDMCHRC, Mathura for the present study.

The diagnosis of chronic obstructive pulmonary disease is made by symptoms in history and confirmed by physical examination, radiographic examination and lung spirometry for airway obstruction by spiroanalyser.

\section{Exclusion Criteria}

Cases excluded from the present study are those with a primary diagnosis of bronchial asthma, lung cancer, known left ventricular dysfunction, poorly controlled hypertension, significant valvular disease and known coronary artery diseases (Angina, Ischaemic changes in resting ECG or documented history of myocardial infarction).

Cases with non-visualisation or poor visualisation of only one or few parameters being studied in the presence of recordable readings of the other parameters are included. Patients with active pulmonary Koch's or history of old pulmonary Koch's were excluded from the study.

\section{Study Protocol}

After recruitment for the study, a thorough physical examination was done and routine investigations were carried out. The patients were subjected to the spirometric examination. The patients who were diagnosed as having chronic obstructive pulmonary disease as per GOLD guidelines with FEV1/FVC 0.7 or less are further divided into 4 groups-

Group I- Patients having FEV/FVC 0.7 or less, but having a FEV1 of more than $80 \%$ of predicted value.

Group II- Patients selected fulfil the above criteria and belong to moderate COPD based on predicted FEV1 (50 - 80\% of predicted value).

Group III- Patients selected fulfil the above criteria and belong to severe COPD based on predicted FEV1 (30 - 50\% of predicted value).

Group IV- Patients selected fulfil the above criteria and belong to very severe COPD based on predicted FEV1 $<<30 \%$ of predicted value).

\section{Electrocardiographic Assessment}

A standard 12-lead electrocardiography obtained for each using a portable ECG machine. The following ECG changes were detected and correlated with spirometric test- a. $\quad$ P-pulmonale pattern ( $\mathrm{P}$-wave amplitude $>2.5 \mathrm{~mm}$ ) in leads II, III, avF;

b. Right axis deviation of QRS complex (beyond +90 degrees).

c. Right ventricular hypertrophy.

d. Right bundle branch block.

e. Low voltage $Q R S$ complexes.

f. Polymorphic p-wave.

\section{Statistical Method}

The data was entered in SPSS version 22 for generating reports and distribution curves of the study population. Chisquare test was used to see how strongly ECG changes were related with spirometric findings of COPD patients. A p-value of less than 0.05 was considered as significant.

\section{RESULTS}

This paper deals with relationship of ECG changes with spirometric parameters in COPD patients.

The study includes $50(\mathrm{~N}=50)$ patients diagnosed as COPD in our tertiary care centre. Out of 50 patients, 43 were male and 7 were female patients.

Maximum number of patients i.e. 27 belonged to $51-60$ years of age group.

As per GOLD criteria mild group included 2 COPD patients, moderate group 14 COPD patients, severe group consisted of 23 COPD patients and very severe group consisted of 11 COPD patients. Further, the patients in each subgroup were studied for ECG changes.

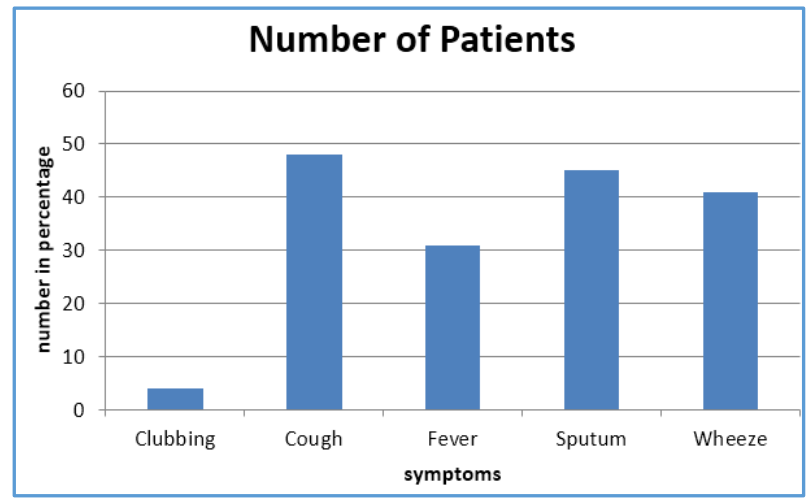

Figure 1. Demonstrates the distribution of patients according to Symptoms Exhibited. The most common Symptom was Cough followed by Sputum Production

\begin{tabular}{|c|c|c|c|}
\hline ECG Changes & Criteria & Number (n= 50) & \% \\
\hline \multirow{2}{*}{ P-pulmonale } & Absent & 16 & 32.0 \\
\cline { 2 - 4 } & Present & 34 & 68.0 \\
\hline $\begin{array}{c}\text { Right axis deviation } \\
\text { of QRS Complex } \\
\text { (Beyond +90 degrees) }\end{array}$ & Absent & 19 & 38.0 \\
\cline { 2 - 4 } & Present & 31 & 62.0 \\
\hline $\begin{array}{c}\text { Right Ventricular } \\
\text { Hypertrophy (RVH) }\end{array}$ & Absent & 40 & 80.0 \\
\cline { 2 - 4 } & Present & 10 & 20.0 \\
\hline $\begin{array}{c}\text { Right bundle branch } \\
\text { block (RBBB) }\end{array}$ & Absent & 34 & 68.0 \\
\cline { 2 - 4 } & Present & 16 & 32.0 \\
\hline $\begin{array}{c}\text { Low voltage of QRS } \\
\text { complex }\end{array}$ & Absent & 24 & 48.0 \\
\cline { 2 - 4 } & Present & 26 & 52.0 \\
\hline Polymorphic p-wave & Absent & 44 & 88.0 \\
\hline \multicolumn{2}{|c|}{ Present } & 6 & 12.0 \\
\hline \multicolumn{2}{|c|}{ Table 1. ECG Changes in COPD Patients } \\
\hline
\end{tabular}


In the current study, the most frequent ECG change observed was P-pulmonale (68\%) and the least common change was Right Ventricular Hypertrophy.

\begin{tabular}{|c|c|c|c|c|c|c|}
\hline \multirow[t]{2}{*}{ 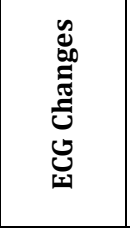 } & \multirow[t]{2}{*}{ } & \multirow[t]{2}{*}{$\begin{array}{l}\text { Dิ } \\
\text { in } \\
\text { 光 } \\
\dot{0} \\
\dot{z}\end{array}$} & \multicolumn{3}{|c|}{ 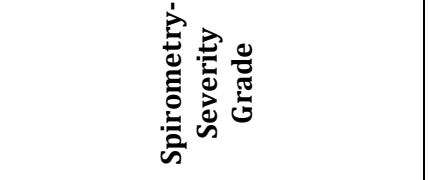 } & \multirow[t]{2}{*}{$\frac{0}{\frac{\pi}{\pi}}$} \\
\hline & & & Grade-2 & Grade-3 & \begin{tabular}{|l|} 
Grade-4 \\
\end{tabular} & \\
\hline \multirow{2}{*}{ 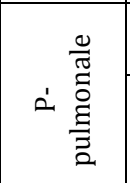 } & Absent & 16 & $\begin{array}{c}13 \\
(81.25 \%) \\
\end{array}$ & $\begin{array}{c}2 \\
(12.50 \%)\end{array}$ & $\begin{array}{c}1 \\
(6.25 \%) \\
\end{array}$ & \multirow{2}{*}{ 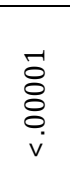 } \\
\hline & Present & 34 & $\begin{array}{c}3 \\
(8.82 \%)\end{array}$ & $\begin{array}{c}22 \\
(64.70 \%)\end{array}$ & $\begin{array}{c}9 \\
(26.47 \%)\end{array}$ & \\
\hline \multirow{2}{*}{$\begin{array}{c}\text { Right axis } \\
\text { deviation } \\
\text { of QRS } \\
\text { complex }\end{array}$} & Absent & 19 & $\begin{array}{c}15 \\
(78.94 \%)\end{array}$ & $\begin{array}{c}3 \\
(15.78 \%) \\
\end{array}$ & $\begin{array}{c}1 \\
(5.26 \%) \\
\end{array}$ & \multirow{2}{*}{$\begin{array}{l}\text { ¿̊ } \\
8 \\
8 \\
\text { v }\end{array}$} \\
\hline & Present & 31 & $1(3.22 \%)$ & $\begin{array}{c}21 \\
(67.77 \%)\end{array}$ & $\begin{array}{c}9 \\
(29.03 \%)\end{array}$ & \\
\hline \multirow{2}{*}{ RVH } & Absent & 40 & $\begin{array}{c}15 \\
(37.50 \%)\end{array}$ & $\begin{array}{c}18 \\
(45.00 \%)\end{array}$ & $\begin{array}{c}7 \\
(17.50 \%) \\
\end{array}$ & \multirow{2}{*}{.235} \\
\hline & Present & 10 & $\begin{array}{c}1 \\
(10.00 \%) \\
\end{array}$ & $\begin{array}{c}6 \\
(60.00 \%) \\
\end{array}$ & \begin{tabular}{|c|}
3 \\
$(30.00 \%)$ \\
\end{tabular} & \\
\hline \multirow{2}{*}{ RBBB } & Absent & 34 & $\begin{array}{c}14 \\
(41.17 \%) \\
\end{array}$ & $\begin{array}{c}17 \\
(50.00 \%) \\
\end{array}$ & \begin{tabular}{|c|}
3 \\
$(8.82 \%)$ \\
\end{tabular} & \multirow{2}{*}{.008} \\
\hline & Present & 16 & $\begin{array}{c}2 \\
(12.50 \%)\end{array}$ & $\begin{array}{c}7 \\
(43.75 \%) \\
\end{array}$ & $\begin{array}{c}7 \\
(43.75 \%) \\
\end{array}$ & \\
\hline \multirow{2}{*}{\begin{tabular}{|c|} 
Low \\
voltage \\
of QRS \\
complex
\end{tabular}} & Absent & 24 & $\begin{array}{c}2 \\
(8.33 \%) \\
\end{array}$ & $\begin{array}{c}15 \\
(62.50 \%)\end{array}$ & $\begin{array}{c}7 \\
(2.16 \%) \\
\end{array}$ & \multirow{2}{*}{.002} \\
\hline & Present & 26 & $\begin{array}{c}14 \\
(53.84 \%)\end{array}$ & $\begin{array}{c}9 \\
(34.61 \%)\end{array}$ & $\begin{array}{c}3 \\
(11.53 \%)\end{array}$ & \\
\hline \multirow{2}{*}{$\begin{array}{l}\text { Polymor } \\
\text { phic p- } \\
\text { wave }\end{array}$} & Absent & 44 & $\begin{array}{c}15 \\
(34.1 \%) \\
\end{array}$ & $\begin{array}{c}18 \\
(41.0 \%) \\
\end{array}$ & \begin{tabular}{|c|}
11 \\
$(25.0 \%)$ \\
\end{tabular} & \multirow[t]{2}{*}{.317} \\
\hline & Present & 6 & $1(16.6 \%)$ & $5(83.4 \%)$ & $0(00.0 \%)$ & \\
\hline
\end{tabular}

In the present study, it was observed that the most frequent ECG changes were P-pulmonale and Right Axis Deviation of QRS complex seen in grade II and III severity, which is statistically significant. However, RVH pattern, RBBB and low voltage were seen less commonly and thus were statistically not significant.

\begin{tabular}{|c|c|c|c|c|c|}
\hline \multirow{2}{*}{$\begin{array}{c}\text { ECG } \\
\text { Changes }\end{array}$} & \multirow{2}{*}{ Criteria } & \multirow{2}{*}{$\begin{array}{c}\text { No. } \\
(n=50)\end{array}$} & \multicolumn{2}{|c|}{ FEV1/FVC } & \multirow[b]{2}{*}{$\begin{array}{c}P \\
\text { value }\end{array}$} \\
\hline & & & $51-60$ & 61-70 & \\
\hline \multirow{2}{*}{ P-pulmonale } & Absent & 16 & $13(56.2 \%)$ & $2(43.7 \%)$ & \\
\hline & Present & 34 & $11(41.2 \%)$ & $23(58.8 \%)$ & \\
\hline \multirow{2}{*}{\begin{tabular}{|c|} 
Right axis \\
deviation of \\
QRS \\
complex
\end{tabular}} & Absent & 19 & $17(89.5 \%)$ & $2(10.5 \%)$ & .000 \\
\hline & Present & 31 & $12(38.7 \%)$ & $19(61.3 \%)$ & .000 \\
\hline \multirow{2}{*}{ RVH } & Absent & 40 & $24(60.0 \%)$ & $16(40.0 \%)$ & \multirow[b]{2}{*}{1.00} \\
\hline & Present & 10 & $6(60.0 \%)$ & $4(40.0 \%)$ & \\
\hline \multirow{2}{*}{ RBBB } & Absent & 34 & $22(64.7 \%)$ & $12(35.3 \%)$ & \multirow[b]{2}{*}{0.56} \\
\hline & Present & 16 & $9(56.2 \%)$ & $7(43.7 \%)$ & \\
\hline \multirow{2}{*}{$\begin{array}{c}\text { Low voltage } \\
\text { of QRS } \\
\text { complex }\end{array}$} & Absent & 24 & $18(75.0 \%)$ & $8(33.3 \%)$ & \multirow[b]{2}{*}{0.09} \\
\hline & Present & 26 & $11(42.3 \%)$ & $13(50.0 \%)$ & \\
\hline \multirow{2}{*}{$\begin{array}{c}\text { Polymorphic } \\
\text { p-wave }\end{array}$} & Absent & 44 & $13(29.5 \%)$ & $31(70.5 \%)$ & \multirow[b]{2}{*}{0.50} \\
\hline & Present & 6 & $1(16.6 \%)$ & $5(83.4 \%)$ & \\
\hline
\end{tabular}

Table 3 denotes that more ECG changes were seen in COPD patients with low FEV1/FVC \% values (probably due to increase in residual volume with reduction in FEV1/FVC ratio).

\section{DISCUSSION}

A prospective observational study of COPD patients was done with the aim to study correlation between ECG changes and spirometric parameters in patients with COPD. Among 50 patients with COPD, maximum number of patients i.e. 27 belonged to 51 - 60 years of age group. Similar finding was reported in study by Banker et al in Gandhinagar.(6)

In the present study most common symptom was cough at the time of presentation followed by cough with sputum production, which is comparable to the study by Jain NK et al.(7)

In the current study, the most frequent ECG change observed was P-pulmonale (68\%) and the next common change was Right Axis Deviation of QRS Complex (beyond +90 degrees). This is in accordance with findings of studies conducted by Gupta et al (2015)(8) and VK Singh et al (1989),(9) which states that $\mathrm{p}$-wave axis $>+90^{\circ}$ is a common ECG abnormality.

On the contrary a study by Kamdar DJ et al (2017) in Gujarat(2) reported that P-pulmonale was observed only in $20 \%$ of the COPD patients. A study by Chappell AG(10) reports that $70 \%$ of cases showed right axis deviation of QRS complex (Beyond +90 degrees).

In the present study, it was observed that the most frequent ECG changes were P-pulmonale and Right Axis Deviation of QRS complex seen in grade II and III severity, which is statistically significant. However, RBBB and low voltage were seen less commonly and thus were statistically not significant. Similar findings were reported by Gupta et al (2015) in Rajasthan(8) and by R Ramakrishna et al in Guntur.(2)

The current study also shows that COPD patients with low FEV1/FVC \% values have more ECG changes in comparison to those with higher FEV1/FVC \% values. And as the severity of airflow obstruction increases (fall in FEV1), ECG changes also becomes more common. A study by VK Singh et al (1989)(9) and Gupta et al (2015)(8) also suggested significant negative correlation between the FEV1/FVC values and the incidence of various electrocardiographic features.

\section{CONCLUSION}

Chronic obstructive pulmonary disease, a broad spectrum of respiratory diseases represents a worldwide problem. Diagnosis of COPD is established on the basis of history and spirometric examination. Forced expiratory volume in the first second (FEV1) along with forced vital capacity (FVC) and FEV1/FVC ratio are important parameters in diagnosing and assessing the severity of the patients with COPD.

The most frequent ECG change observed is P-pulmonale and Right Axis Deviation of QRS complex seen in grade II and III severity. So, ECG can be considered as an alternative parameter when spirometry is not available. 


\section{REFERENCES}

[1] Rachakonda R, Beri S, Kalyankumar PV. Study of ECG and echocardiographic findings in COPD patients in a tertiary care centre. J Evolution Med Dent Sci 2016;5(24):1276-80.

[2] Kamdar DJ, Patel DK. A study of the clinical profile of 50 patients of COPD with correlation between clinical, radiological and spirometric evaluation. Int J Res Med Sci 2017;5(5):1802-7.

[3] Cho SH, Lin HC, Ghoshal AG, et al. Respiratory disease in Asia-Pacific region: cough as the key symptom. Allergy Asthma Proc 2016;37(2):131-40.

[4] BMJ Best Practice. Global Initiative for Chronic Obstructive Lung Disease (GOLD) criteria. 2017. (Cited April 4 , 2018). https://bestpractice.bmj.com/topics/en-us/7/criteria

[5] Rachaiah NM, Rachaiah JM, Krishnaswamy RB. A correlative study of spirometric parameters and ECG changes in patients with chronic obstructive pulmonary disease. Int J Biol Med Res 2012;3 (1):1322-6.
[6] Banker H, Verma A. Electrocardiographic changes in COPD. NHL Journal of Medical Sciences 2013;2(2):558.

[7] Jain J, Apte S, Soni P, et al. A study of correlation between the ECG changes with the duration and severity of chronic obstructive pulmonary disease. Journal of Evolution of Medical and Dental Sciences 2014;3(7):1739-44.

[8] Gupta D, Agrawal P, Kothari RP, et al. Electrocardiographic changes in chronic obstructive pulmonary disease - correlation with air flow limitation. IOSR Journal of Dental and Medical Sciences 2015;14(9):49-52.

[9] Singh VK, Jain SK. Effects of airflow limitation on the electrocardiogram in chronic obstructive pulmonary disease (COPD). Indian J Chest Dis \& All Sci 1989;31(1):1-8.

[10] Chappell AG. The electrocardiogram in chronic bronchitis and emphysema. Brit Heart J 1996;28 (4):517-22. 